\title{
MARTABAT PEREMPUAN MINANGKABAU DALAM NOVEL TENGGELAMNYA KAPAL VAN DER WIJCK KARYA HAMKA
}

\author{
Hidayah Budi Qur'ani \\ Universitas Muhammadiyah Malang \\ qurani@umm.ac.id
}

\begin{abstract}
ABSTRAK
Tulisan ini membahas tentang martabat tokoh perempuan dalam novel Tenggelamnya Kapal Van Der Wijk karya Hamka yang berlatar budaya Minangkabau. Bentuk-bentuk martabat perempuan digambarkan melalui Hayati sebagai tokoh utama dalam novel Tenggelamnya Kapal Van Der Wijk karya Hamka. Tokoh Hayati dibesarkan dalam lingkungan keluarga Minangkabau yang menjunjung tinggi tradisi matrilineal. Tradisi matrilineal perempuan Minangkabau diwajibkan mempunyai sifat-sifat yang sudah ditetapkan dalam adat. Hal itu bertujuan agar perempuan Minangkabau dapat menjadi bundo kanduang atau perempuan yang memiliki sifat-sifat keibuan sekaligus sifat-sifat kepemimpinan, yang cerdas, bijaksana, dan berhati mulia. Metode yang digunakan dalam penelitian ini adalah deskriptif analitik dengan data novel Tenggelamnya Kapal Van Der Wijk karya Hamka. Analisis data dilakukan dengan cara penyeleksian data, pemaparan data, dan penarikan kesimpulan dalam novel tersebut. Hasil penelitian martabat tokoh perempuan yang digambarkan melalui tokoh Hayati memperlihatkan adanya sifat-sifat yang sesuai dengan budaya Minangkabau. Sebagai seorang individu, martabat tokoh Hayati digambarkan sebagai seorang perempuan yang dapat menjaga pergaulan, berilmu, dan rendah hati dan menjaga kehormatan.
\end{abstract}

Kata Kunci: Novel, Martabat Perempuan, Budaya Minangkabau

\section{A. Pendahuluan}

Masyarakat Minangkabau merupakan masyarakat yang menganut tradisi matrilineal dan komunal. Matrilenal dapat diartikan sebagai tradisi yang menganut garis keturunan ibu dalam sistem kekerabatannya. Dengan kata lain, perempuan dalam budaya Minangkabau mempunyai peranan penting dalam mengambil setiap keputusan. Perkawinan dalam tradisi matrilineal mengharuskan kedua belah pihak baik laki-laki maupun perempuan menjadi bagian dari kaumnya (garis keturunan ibu). Di sisi lain, dalam tradisi komunal Minangkabau, istri memiliki status yang sama dengan suami dan tidak sepenuhnya tergantung pada suaminya. Pada tahap sebelum perkawinan, pihak perempuanlah yang dianggap memiliki kepentingan lebih besar dalam perkawinan. Pihak perempuanlah yang menjadi pemrakarsa dalam perkawinan tersebut. Demikian pula dalam hal kepemilikan harta warisan. Perempuan Minangkabau memiliki hak atas harta pusaka peninggalan nenek moyangnya. Sementara itu, pihak laki-laki hanya memiliki hak mengusahakan atau menggunakan (Navis, 1984: 193). 
Lingua Rima: Jurnal Pendidikan Program Studi Bahasa dan Sastra Indonesia Vol.8 No.1 Januari 2019

Perempuan Minangkabau apabila sudah berumah tangga atau bersuami akan disebut dengan bundo kanduang (Desmaliza,dkk, 2013: 10). Bundo kanduang mempunyai arti ibu sejati yang memiliki sifat keibuan dan kepemimpinan. Selain itu, perempuan Minangkabau memiliki pemikiran jauh ke depan dan konsisten dalam mengambil keputusan. Di sisi lain, perempuan Minangkabau adalah seorang yang pemurah dan penyantun. Apa yang dikerjakannya dapat dipedomani dan bermanfaat bagi orang lain. Perempuan tidak hanya berperan sebagai ibu dalam kehidupan sehari-hari. Perempuan juga mempunyai peranan sebagai isteri, pendamping setia bagi laki-laki sebagai pendamping hidupnya, dan ia juga berperan sebagai teman dan kekasih terhadap orang-orang yang dicintainya. Berbagai peran tersebut harus dilakoni perempuan secara seimbang dan penuh tanggung jawab. Namun pada kenyataannya, perempuan hidup ditengah permasalahan yang cukup pelik karena tidak mampu melaksanakan peran tersebut secara seimbang dan penuh tanggung jawab. Persoalan yang pelik tersebut sering membuat perempuan kehilangan keseimbangan dan mengalami keresahan dalam dirinya.

Oleh karena itu, dalam tradisi matrilineal sudah tentu sangat menjunjung tinggi peran perempuan. Perempuan sebagai bundo kanduang harus mampu menjalankan perannya dalam kehidupan sehari-hari. Selain menjalankan kodratnya sebagai seorang perempuan, perempuan Minangkabau harus mampu menjaga harta pusaka peninggalan nenek moyang dan harus memiliki jiwa kepemimpinan. Hal itu membuat perempuan Minangkabau mempunyai tanggung jawab yang lebih besar daripada laki-laki. Oleh karena itu, perempuan Minangkabau harus memiliki dasar ilmu dan agama yang kuat agar mampu menjalankan peran secara seimbang.

Karya sastra (Desmaliza, dkk, 2013: 8-9) menampilkan pengalaman dan persoalan hidup manusia yang begitu rumit dan kompleks. Karya sastra merupakan hasil dialog, kontemplasi, dan reaksi pengarang terhadap lingkungan dan kehidupan. Karya sastra mencerminkan persoalan-persoalan kehidupan hingga dapat menyentuh hati para pembacanya. Salah satu aspek kehidupan tersebut adalah masalah perempuan, seperti masalah gender, emansipasi wanita, dan tokoh perempuan karena masalah perempuan tidak pernah habis untuk dibicarakan. Walau berupa khayalan, tidak benar jika karya sastra dianggap sebagai hasil kerja lamunan belaka, melainkan penghayatan dan perenungan secara intens, perenungan terhadap hakikat hidup dan kehidupan, perenungan yang dilakukan dengan penuh kesadaran dan tanggung jawab oleh karena itu karya sastra dikatakan sebagai karya imajinatif yang dilandasi kesadaran dan tanggung jawab dari segi kreatifitas sebagai karya seni. Sastra 
Lingua Rima: Jurnal Pendidikan Program Studi Bahasa dan Sastra Indonesia

Vol.8 No.1 Januari 2019

menawarkan model-model kehidupan sebagaimana yang diidealkan oleh pengarang sekaligus menunjukkan sosoknya sebagai karya seni yang berunsur estetik dominan.

Karya sastra Indonesia warna lokal Minangkabau telah menegaskan pentingnya sosok perempuan. Tokoh perempuan dihadirkan dalam berbagai profil. Martabat perempuan Minangkabau dalam sastra lokal Minangkabau nampak begitu kuat sesuai dengan fungsinya di dalam realita. Martabat perempuan dalam karya sastra Minangkabau digambarkan dalam sosok perempuan sebagai individu maupun perempuan sebagai anggota masyarakat. Seorang perempuan harus menjaga nama baik dan martabatnya sebagai perempuan yang mulia. Fenomena perempuan yang dapat dianalisis dengan citra perempuan Minangkabau menurut Hakimy (1991: 83-91) adalah: (1) martabat perempuan Minangkabau sebagai individu: (a) ingek dan jago pado adat, (b) berilmu, bermakrifat, berfaham, ujud yakin pado Allah, (c) murah dan mahal dalam laku dan parangai yang berpatutan, (d) kayo miskin pado hati dan kebenaran,(e) sabar dan ridha, (f) imek dan jimek lunak lambuik bakato-kato, (2) martabat perempuan Minangkabau sebagai anggota masyarakat: (a) bersifat kebenaran, (b) bersifat jujur, dipercayai lahir dan batin, (c) bersifat cerdik, (d) pandai berbicara, (e) mempunyai sifat malu.

Begitu halnya pada novel Tenggelamnya Kapal Van Der Wijk karya Hamka yang menggambarkan citra perempuan Minangkabau melalui sosok Hayati. Hayati merupakan tokoh perempuan yang dibesarkan dengan tradisi matrilineal yang mengharuskan perempuan memiliki sifat-sifat yang sesuai dengan adat. Novel Tenggelamnya Kapal Van Der Wijk karya Hamka menceritakan kehidupan seorang perempuan Minang bernama Hayati. Hayati merupakan seorang perempuan asli Minangkabau yang mencintai laki-laki bernama Zainuddin yang merupakan seorang campuran Minangkabau dan Makassar. Oleh karena itu, Hayati tidak dapat menikah dengan Zainuddin. Hayati kemudian dijodohkan dengan Aziz yang sama-sama berasal dari Minangkabau. Kehidupan rumah tangga Aziz dan Hayati tidaklah baik karena Hayati mempunyai sifat yang sangat teguh memegang adat matrilineal sedangkan Aziz adalah laki-laki modern yang senang berkumpul dengan teman-temannya. Oleh karena itu, kehidupan rumah tangga mereka tidak harmonis karena Hayati sangat berpegang teguh pada adat Minangkabau yang mengharuskan ia mempunyai martabat seperti Bundo Kanduang.

Fokus tulisan ini adalah membahas tentang martabat tokoh perempuan sebagai individu. Penelitian ini menjawab permasalahan mengenai bentuk-bentuk citra perempuan Minangkabau dalam novel Tenggelamnya Kapal Van Der Wijk karya Hamka. Hal tersebut 
Lingua Rima: Jurnal Pendidikan Program Studi Bahasa dan Sastra Indonesia

Vol.8 No.1 Januari 2019

disebabkan karena seorang perempuan merupakan individu yang mempunyai peranan kompleks. Selain menjalankan kodratnya sebagai seorang perempuan, ia juga harus menjalankan tugasnya sebagai individu di dalam adat masyarakat. Perempuan Minangkabau sebagai seorang individu harus mempunyai sifat-sifat yang sudah ditentukan oleh adat. Perempuan haruslah mampu menjadi seorang yang pandai dalam bergaul, berilmu dan beragama, pandai menjaga tingkah laku dan pandai dalam bertutur kata, serta pandai menjaga harkat dan martabat.

\section{B. Kajian Pustaka}

Novel adalah salah satu jenis ragam prosa yang pada dasarnya merupakan satu bentuk cerita panjang, melibatkan banyak tokoh dengan masing-masing wataknya dan merupakan suatu rangkaian peristiwa yang berkaitan dengan kehidupan manusia (Rahayu, 2014: 45). Lebih lanjut, Akbar, dkk, (2013: 58) menjelaskan bahwa novel merupakan cerita fiksi yang mengangkat permasalahan kompleks tentang kehidupan dan tersusun atas unsur intrinsik dan ekstrinsik. Kedua unsur tersebut disusun secara padu dan saling terikat dalam mengungkapkan setiap jalinan peristiwa.

Martabat perempuan Minangkabau sebagai individu menurut Hakimy (1991: 83-91) antara lain (1) ingek dan jago pado adat, (2) berilmu, bermakrifat, berfaham, ujud yakin pado Allah, dan (3) murah dan mahal dalam laku dan parangai yang berpatutan. Ingek dan jago pado adat berarti bahwa seorang perempuan harus berhati-hati dalam setiap perkataannya. Perempuan harus menjaga tutur kata, tingkah laku, dan penglihatan. Seorang perempuan harus senantiasa menjauhkan diri dari tingkah laku yang tidak sesuai dengan adat dan kebudayaan Minangkabau. Sebab, sesuatu yang dilarang oleh adat Minangkabau di dalam pergaulan sehari-hari, juga dilarang oleh agama Islam (syarak) Hakimy (1991: 87).

Berilmu, bermakrifat, berfaham, ujud yakin pado Allah menurut Hakimy (1991: 88) berarti bahwa seorang perempuan haruslah berilmu pengetahuan, terutama dalam bidang keperempuaan itu sendiri. Bermarifat berarti haruslah menjadi perempuan yang taat menyembah Allah. Berfaham mempunyai arti pandai bergaul dan menjaga perkataan yang akan menyakiti orang lain dan menyimpan rahasia yang patut dirahasiakan. Lebih lanjut Hakimy (1991:88) menjelaskan bahwa ujud dan yakin mengetahui ujud Allah dan yakin di dalam kehidupab beragama dan beradat, sehingga menjadi pakaian dalam kehidupan seharihari. keseluruhan dari macam martabat yang kedua ini harus dihayati dalam kehidupan rumah tangga dan diluar kehidupan rumah tangga. 
Murah dan mahal dalam laku dan parangai yang berpatutan oleh Hakimy (1991:89) diartikan sebagai seorang perempuan di dalam pergaulan sehari-hari, ramah dan rendah hati, tidak angkuh dan sombong, baik sesamanya maupun pada laki-laki. Akan tetapi, ada waktu yang harganya mahal yaitu tidak suka dipermainkan laki-laki, dirayu dan dibujuk dengan segala bentuk rayuan dan tipuan. Selalu menjaga kehormatannya yang dibentengi sifat malu dan sopan dan budi pekerti yang mulia.

\section{Metode Penelitian}

Jenis penelitian ini adalah penelitian kualitatif. Penelitian kualitatif adalah penelitian yang dilakukan dengan tidak menggutamakan angka-angka, tetapi menggutamakan kedalaman penghayatan terhadap objek yang diteliti dan dikaji secara empiris. Oleh karena itu, untuk mencapai masalah yang diteliti maka metode yang digunakan metode deskriptif. Sumber data penelitian ini yaitu novel Tenggelamnya Kapal Van Der Wijk karya Hamka yang akan diseleksi sebagai bahan analisis. Selanjutnya, data dalam penelitian ini yaitu teks dan kutipan tentang deskripsi citra perempuan Minangkabau dalam novel Tenggelamnya Kapal Van Der Wijk karya Hamka. Sumber data yang digunakan dalam penelitian ini adalah sumber data primer. Data primer adalah data utama yang diproleh langsung dari sumbernya tanpa lewat perantara.

\section{Pembahasan}

Martabat perempuan Minangkabau sebagai individu menurut Hakimy (1991: 83-91) antara lain (1) ingek dan jago pado adat, (2) berilmu, bermakrifat, berfaham, ujud yakin pado Allah, (3) murah dan mahal dalam laku dan parangai yang berpatutan, dan (4) kayo miskin pado hati dan kebenaran.

Novel Tenggelamnya Kapal van der Wijck karya Hamka menceritakan tokoh perempuan bernama Hayati yang tumbuh dalam budaya Minangkabau. Sebagai seorang perempuan yang tumbuh dalam tradisi matrilineal, Hayati paham benar hal-hal yang harus ia lakukan dan hindari demi menjaga martabat keluarga. Ia juga harus menjaga setiap tingkah lakunya agar dapat menjadi panutan bagi sesamanya. Hayati tidak boleh berbuat hal-hal yang dapat memalukan dan harus menjaga nama baik keluarga.

\section{Ingek dan Jago Pado Adat}

Pada Novel Tenggelamnya Kapal van der Wijck karya Hamka, tokoh Hayati digambarkan mempunyai keenam sifat tersebut. Sifat yang pertama adalah ingek dan jago pado adat yang berarti Seorang di Minangkabau selalu ingat dan hati-hati terhadap adatnya jangan sampai rusak. Dalam pergaulan antara perempuan sesama perempuan, apalagi 
Lingua Rima: Jurnal Pendidikan Program Studi Bahasa dan Sastra Indonesia

Vol.8 No.1 Januari 2019

perempuan dan laki-laki, baik famili maupun orang lain, selalu menjauhkan diri serta hati jangan bergaul bebas, terutama bagi perempuan yang masih gadis, serta menjauhi diri yang bersifat sumbang di dalam pergaulan yang berbuat salah menurut pandangan adat dan agama Islam.

Novel Tenggelamnya Kapal van der Wijck karya Hamka digambarkan tokoh Hayati sangat pandai dalam bergaul. Ia mempunyai sahabat bernama Khadijah. Dengan sahabatnya, Hayati selalu bertukar pikiran tanpa saling menyakiti. Hayati dan Khadijah mempunyai hubungan yang sangat akrab. Keduanya masih saling mengirim surat meskipun mereka sudah mempunyai suami dan mempunyai kehidupan sendiri-sendiri. Hayati selalu menceritakan kehidupannya setelah berpisah dengan Khadijah dan memulai kehidupan rumah tangga mereka masing-masing. Mereka berdua saling berbagi cerita dan saling bertukar pendapat. Hayati selalu bercerita perihal kehidupan rumah tanggany kepada Khadijah. Selain itu, ia juga suka bercerita mengenai buku-buku dan hikayat-hikayat yang sering dibacanya (Hamka, 1984:100).

Meskipun sudah berpisah dengan sahabatnya dan memiliki kehidupan rumah tangga masing-masing, Hayati lantas tidak memutuskan hubungannya dengan Khadijah. Hayati selalu mengirim surat kepada Khadijah. Dalam suratnya, Hayati sering mengajak Khadijah untuk berdiskusi mengenai kehidupan rumah tangga atau berdiskusi mengenai buku-buku bacaan yang dibaca oleh Hayati.Tokoh Hayati selalu menjaga pergaulan terhadap sesamanya. Hal itu tergambar dalam pergaulannya, Hayati selalu menjaga setiap perkataan dan perilakunya. Ia selalu menjaga perkataan dan perilakunya kepada teman perempuan maupun teman laki-laki. Ia tidak menyakiti teman-temannya dengan perkataan maupun perbuatan. Terhadap teman laki-laki yang bukan muhrim, Hayati selalu menjaga pandangan dan perilakunya. Ia tidak berani berdua saja dengan laki-laki yang bukan suaminya meskipun lakilaki tersebut merupakan orang yang dicintainya.

Hal tersebut sesuai dengan pendapat Hakimy (1991: 87) yang menyatakan bahwa seorang perempuan harus berhati-hati dalam setiap perkataannya. Perempuan harus menjaga tutur kata, tingkah laku, dan penglihatan. Seorang perempuan harus senantiasa menjauhkan diri dari tingkah laku yang tidak sesuai dengan adat dan kebudayaan Minangkabau. Sebab, sesuatu yang dilarang oleh adat Minangkabau di dalam pergaulan sehari-hari, juga dilarang oleh agama Islam (syarak).

\section{Berilmu, Bermakrifat, Berfaham, Ujud Yakin Pado Allah}


Martabat perempuan yang kedua adalah perempuan harus mempunyai sifat berilmu, bermakrifat, berfaham, ujud yakin pado Allah. berilmu, bermakrifat, berfaham, ujud yakin pado Allah dapat diartikan sebagai perempuan Minangkabau harus mau memperdalam ilmu agama dan selalu mendekatkan diri kepada Allah. Dalam setiap perilaku sehari-hari harus berlandaskan agama dan ilmu pengetahuan agar menjadi perempuan yang mempunyai harga diri.

Pada novel Tenggelamnya Kapal van der Wijck karya Hamka, tokoh Hayati juga digambarkan sebagai seorang perempuan yang berilmu. Dalam kutipan novel digambarkan bahwa perempuan-perempuan di Batipuh tidak serta merta mengindahkan kewajiban mereka untuk tidak menuntut ilmu. Meskipun sebagai perempuan, masyarakat Batipuh selalu menekankan pada anak perempuan mereka untuk menuntut ilmu. Dalam hal ini, menuntut ilmu yang dimaksud adalah mengaji. Setiap perempuan diwajibkan untuk menuntut ilmu agama. Setiap hari Jumat semua perempuan berbondong-bondong untuk menuntut ilmu agama. Hal tersebut juga terjadi pada Hayati. Meskipun Ibu maupun kerabat tua mengkhawatirkan akan terjadi hal yang buruk padanya, tetapi Hayati bersikukuh untuk menuntut ilmu. Oleh karena itu, ibunya menyuruh dayang-dayang untuk mengiringi Hayati pergi belajar mengaji (Hamka, 1984:29).

Perempuan di Minangkabau termasuk Hayati selalu mempelajari ilmu agama. Setiap hari Jumat, Hayati selalu pergi ke Batipuh untuk belajar memperdalam ilmu agama. Ia bersama dayang-dayang (pengiring) pergi memperdalam ilmu agama dengan semangat meskipun turun hujan. Ia menyadari bahwa ilmu yang diperoleh merupakan bekal kehidupan yang bermanfaat bagi masa depan.Hal tersebut sesuai dengan pendapat Hakimy (1991: 88) yang menyatakan bahwa seorang perempuan haruslah berilmu pengetahuan, terutama dalam bidang keperempuaan itu sendiri. Bermarifat berarti haruslah menjadi perempuan yang taat menyembah Allah. Berfaham mempunyai arti pandai bergaul dan menjaga perkataan yang akan menyakiti orang lain dan menyimpan rahasia yang patut dirahasiakan.

\section{Murah dan Mahal dalam Laku dan Parangai yang Berpatutan}

Martabat perempuan Minangkabau sebagai individu yang ketiga adalah murah dan mahal dalam laku dan parangai yang berpatutan. Hal ini dapat diartikan bahwa perempuan Minangkabau harus dapat menempatkan diri dalam lingkungan pergaulan. Perempuan Minangkabau tidak boleh angkuh dan sombong. Akan tetapi, ada saatnya perempuan Minangkabau juga harus menunjukkan bahwa ia tidak dapat dirayu dan dibujuk oleh laki-laki. 
Lingua Rima: Jurnal Pendidikan Program Studi Bahasa dan Sastra Indonesia Vol.8 No.1 Januari 2019

Dalam novel Tenggelamnya Kapal van der Wijck karya Hamka ketika Hayati berkirim surat dengan Zainuddin. Novel tersebut menggambarkan bahwa meskipun Hayati mencintai Zainuddin, tetapi ia lantas tidak menunjukkan bahwa dirinya perempuan yang mudah untuk dirayu. Ketika Zainuddin mengutarakan perasaan cintanya kepadanya, Hayati lantas tidak dijawab begitu saja oleh Hayati meskipun ia juga mempunyai perasaan yang sama. Hayati lebih memilih untuk mengajak Zainuddin membicarakan langsung mengenai permasalaha ini. Hayati tidak serta-merta menemui Zainuddin seorang diri, tetapi ia mengajak adikknya agar tidak disangka berbuat yang kurang patut (Hamka, 1984: 33)

Uraian di atas menunjukkan bahwa tokoh Hayati merupakan seorang yang sangat menjaga harkat dan martabatnya. Meskipun Hayati juga mencintai Zainudiin, tetapi ia tidak lantas menurunkan harga dirinya dengan membalas surat cinta Zainuddin. Hayati dengan tegas mengajak Zainuddin untuk membicarakan hal serius tersebut langsung dengan Zainudin. Ia tidak ingin menjadi perempuan yang mudah dirayu dengan kata-kata manis oleh laki-laki. Hal tersebut sesuai dengan apa yang telah dikemukakan oleh Hakimy (1991:89) bahwa murah dan mahal dalam laku dan parangai yang berpatutan dapat diartikan sebagai seorang perempuan di dalam pergaulan sehari-hari, ramah dan rendah hati, tidak angkuh dan sombong, baik sesamanya maupun pada laki-laki. Akan tetapi, ada waktu yang harganya mahal yaitu tidak suka dipermainkan laki-laki, dirayu dan dibujuk dengan segala bentuk rayuan dan tipuan. Selalu menjaga kehormatannya yang dibentengi sifat malu dan sopan dan budi pekerti yang mulia.

\section{E. Simpulan dan Saran}

Sebagai seorang individu, perempuan Minangkabau harus mempunyai tiga sifat yang melekat dalam dirinya. Ketiga sifat tersebut adalah antara lain (1) ingek dan jago pado adat, (2) berilmu, bermakrifat, berfaham, ujud yakin pado Allah, dan (3) murah dan mahal dalam laku dan parangai yang berpatutan. Sesuai dengan latar budayanya, novel Tenggelamnya Kapal van der Wijck karya Hamka menggambarkan kehidupan perempuan Minangkabau. Penggambaran kehidupan perempuan Minangkabau diwakili oleh tokoh utama bernama Hayati. Hayati digambarkan dalam novel merupakan tokoh perempuan yang memiliki tiga sifat perempuan Minangkabau yang dipegang teguh. Sikap tokoh Hayati sangat sesuai dengan adat Minangkabau yang menjunjung tinggi martabat perempuan. Tokoh Hayati digambarkan sebagai perempuan yang memegang teguh martabat perempuan Minangkabau dalam hal apapun. Ia mampu menjaga kehormatan diri sebagai perempuan dan kehormatan diri sebagai bagian dari masyarakat Minangkabau. 
Untuk peneliti selanjutnya, diharapkan dapat mengembangkan penelitian ini agar lebih bervariasi temuan yang didapat. Meskipun dengan objek yang sama, diharapakan peneliti selanjtnya mampu mengembangkan permasalahan yang diangkat. Tidak menutup kemungkinan bahwa penelitian selanjutnya akan membahas dengan menggunakan teori yang sama. Akan tetapi, diharapkan jika menggunakan teori yang sama maka objek kajian harus lebih bervariasi agar dapat menambah temuan yang sudah ada sebelumnya.

\section{F. Daftar Pustaka}

Akbar, S., \& Winarni, R. (2013). Kajian Sosisologi Sastra dan Nilai Pendidikan Dalam Novel "Tuan Guru" Karya Salman Faris. Jurnal Pendidikan Bahasa dan Sastra, 1(1), 54-68.

Desmaliza, Bakhtaruddin Nst., Hamidin. 2013. "Karakteristik Perempuan Minangkabau dalam Kaba Siti Kalasum Karya Sjamsudin St. Radjo Endah" dalam Jurnal Pendidikan Bahasa dan Sastra Indonesia, Vol. 1 No. 2 Maret 2013; Seri A 1-76.

Hakimy, Idrus. 1991. Pegangan Penghulu, Bundo Kanduang dan Pidato Alua Pasambahan Adat di Minangkabau. Bandung: PT Remaja Rosdakarya.

Hamka, 1984. Tenggelamnya Kapal van der Wijck. Jakarta: PT Bulan Bintang.

Navis, A.A. 1984. Alam Terkembang Jadi Guru: Adat dan Kebudayaan Minangkabau. Jakarta: PT Pustaka Gratifipers.

Rahayu, I. (2014). Analisis Bumi Manusia Karya Pramoedya Ananta Toer dengan Pendekatan Mimetik. Deiksis Jurnal Pendidikan Bahasa dan Sastra Indonesia, 1(1). 